\title{
THE CAFFEINE TEST OF ISOLATED HUMAN MUSCLE IN RELATION TO MALIGNANT HYPERTHERMIA
}

\author{
W. KALOW, B.A. BRITT, AND A. RichTER
}

MALIGNANT Hypenthermia ${ }^{1,2}$ or malignant hyperpyrexia, is a rare but often fatal complication of general anaesthesia, characterized by tachycardia, a dramatic rise of body temperature and often muscle stiffness or rigidity. Halothane has initiated this syndrome more often than other agents. Most of the available pedigrees suggest an autosomal dominant inheritance of the predisposition, a few solely on the basis of hyperthermic episodes during surgery and family history, ${ }^{3.4}$ the majority additionally or solely on the basis of elevations in the plasma levels of creatinekinase (CK) or other evidence of myopathy,i-14 In view of the non-specificity of CK elevations, it may not be surprising that there are sporadic cases $^{4,15}$ and that some pedigrees do not fit the concept of autosomal dominance. ${ }^{16-18}$ It has been suspected that there are several basic defects which may lead to a similar clinical picture..$^{9,19,20}$

In an effort to obtain a clue to the pathogenesis of malignant hyperthermia, it was decided in 1970 to try a pharmacological assay of isolated skeletal muscle besides numerous other investigations. After testing various drugs and drug combinations which do, or might, affect skeletal muscle, it was found that the contracture produced by caffeine could serve to distinguish between muscle from normal subjects and those susceptible to malignant hyperthermia. ${ }^{19}$ Following the report of this observation, other investigators published different pharmacological tests of muscle for the same purposes. ${ }^{21-20}$ We have continued to use the caffeine test in an essentially unchanged manner from its first inception. Our experiences of over six years of using the test are reported because they throw a new light upon the in-born errors which may lead to malignant hyperthermia; in particular, they show conclusively that the prevailing concepts of a simple Mendelian dominance of the predisposition for malignant hyperthermia are inadequate.

\section{Materials and Methods}

(a) Subjects

The caffeine test was performed with human striated muscle obtained from $\mathbf{7 4}$

From The Departments of Pharmacology and Anaesthesia, Faculty of Medicine, University of Toronto.

The initial phase of this work was supported by Grant \#MA-2441 from the Medical Research Council of Canada, the final phase by a Grant from the Muscular Dystrophy Association of Canada. Sustaining support was provided by the Department of Pharmacology, University of Toronto.

- Recommendations are being worked out to suit various investigators known to be currently engaged in muscle tests for malignant hyperthermia. Future standardized tests will presumably differ from that described here by using increasing concentrations of caffeine consecutively without resting pause between applications and by avoiding exposure of specimens to ice-cold Ringer's solution. 
persons, representing several categories of subjects. The first consisted of ten patients (six males and four females, age averaging 30.4 and ranging from 5 to 47 years) who had fully recovered from an attack of malignant hyperthermia ( $\mathrm{MH}$ ) and who were reported to have had at least some muscle rigidity during the hyperthermic episode ("MHr patients"). There were four patients (three males aged 25, 40 and 53 , and one female aged 60 years) after recovery from $\mathrm{MH}$ for whom no rigidity was reported ("MHn patients"). There were 23 relatives of MHr patients ( 17 males and 6 females, age averaging 30.5 and ranging from 16 to 53 years), and two relatives of MHn patients (two males, aged 15 and 42). Most of these MH-related subjects travelled from other parts of North America to Toronto, specifically to be admitted to the Toronto General Hospital for various investigations including the taking of the muscle biopsy specimen. Another group consisted of 21 patients with manifest or suspected muscle disease other than $\mathrm{MH}$ of whom a muscle biopsy was required for diagnostic purposes ( 15 males and 6 females, age averaging 44.4 and ranging from 19 to 79 years); the term "Other Myopathies" will be used to refer to this group. Some data obtained with members of this group will be the subject of a separate publication but, as will be shown below, they could be considered a control population for the purposes of the present study. Finally, there were 14 surgical patients (two males, ten females and two of unrecorded sex; average age 53.7 years, ranging from 19 to 83 years), who were undergoing amputating operations of various kinds as, for instance, limb removal after trauma or radical mastectomy for mammary carcinoma. This group, or muscle specimens from this group, will be referred to as "amputations."

\section{(b) Specimens}

Muscle specimens from MH patients and their relatives were predominantly from the quadriceps muscle. The other myopathies supplied as a rule either quadriceps or deltoid or tibialis anterior muscle, while the various surgical cases and amputations supplied most often pectoralis or intercostal muscle.

Initially, chance delivery of muscle specimens with obliquely cut fibres caused several test failures; thereafter, the surgeons paid careful attention to the direction of the fibres when collecting the specimens. After freeing the muscle surface from fascia and fat, suture silks were tied around the ends of the bundle to be removed; after cutting across near one tie, its thread was used as a handle to slightly tense the specimen during removal. We learned through the failures that cautery at or near the specimen had to be avoided; if possible, bleeding was stopped after and not during removal of the specimen.

In the operating room, the excised specimens were either put into ice-cold Ringer's solution or into a dry test tube and transported into the laboratory. The time elapsed between excision and further processing in the laboratory was about ten minutes. The specimen was trimmed and divided into two pieces to permit measurements in duplicate. The size of each muscle strip was approximately $3 \times 5 \times 20 \mathrm{~mm}$, each weighing roughly $0.3 \mathrm{~g}$, with a range from 0.2 to $0.4 \mathrm{~g}$. In trimming human muscle for the test, it was found necessary to make specifically sure that the direction of the long cut ran parallel to the fibres. 
TABLE I

COMPOSTTION OF RiNGER'S SOLUTION

\begin{tabular}{lcr}
\hline \hline Ingredients & $\mathrm{g} / 1$ & $\mathrm{mM}$ \\
\hline $\mathrm{NaCl}$ & 6.90 & 118.1 \\
$\mathrm{KCl}$ & 0.25 & 3.4 \\
$\mathrm{CaCl}{ }_{2} .6 \mathrm{H}_{2} \mathrm{O}$ & 0.55 & 2.5 \\
$\mathrm{NaHCO}_{3}$ & 2.10 & 25.0 \\
$\mathrm{KH}_{2} \mathrm{PO}_{4}$ & 0.16 & 1.2 \\
$\mathrm{MgSO}_{4} .7 \mathrm{H}_{2} \mathrm{O}$ & 0.20 & 0.8 \\
$\mathrm{Glucose}^{2}$ & 2.00 & 11.1 \\
pH of medium adjusted to 7.4 \\
\multicolumn{2}{l}{} \\
at $22^{\circ} \mathrm{C}$ \\
Gas: $95 \% \mathrm{O}_{2}+5 \% \mathrm{CO}_{2}$ \\
\hline
\end{tabular}

\section{(c) Materials and their arrangements}

For the pharmacological testing, each muscle strip was immersed in $30 \mathrm{ml}$ of a Ringer's solution adapted for human tissue; its composition is shown in Table I. The specimen was secured by a silk suture thread to an electrode housing and submerged with the housing into the tissue bath. The upper end of the muscle was connected by suture silk to a Grass force displacement transducer, (ST-10 dC). Oxygen containing 5 per cent carbon dioxide was bubbled through the solution. The $\mathrm{pH}$ was 7.4. All routine tests were done at room temperature, i.e. at $22^{\circ} \mathrm{C}$ as established by central air conditioning. For occasional tests at higher temperatures, the test chamber and all inflowing solutions were warmed with the help of a waterbath.

Caffeine in the form of a powder was obtained from Eastman Kodak Co. Amounts of 621,310 or $155 \mathrm{mg}$ were weighed and dissolved with the aid of stirring in $100 \mathrm{ml}$ of Ringer's solution immediately prior to use. The concentrations thus obtained were 32,16 or $8 \mathrm{mM}$, respectively; $32 \mathrm{mM}$ was the maximum concentration that could be prepared. Lower concentrations were obtained by diluting a stock solution with Ringer's solution rather than by weighing caffeine powder.

In the earlier experiments, i.e. in about one third of the total, d-tubocurarine chloride (Tubarin, Burroughs Wellcome Ltd.) was added to the bath to yield a final concentration of $0.13 \mathrm{mM}$. If succinylcholine chloride (Sigma Chemical Comp.) was used, solutions were freshly prepared; its final concentration was $0.1 \mathrm{mM}$.

The system was exposed to halothane (Fluothane, Ayerst) in fixed concentration by adding 1 per cent to the bubbling gas with the help of a vaporizer (Fluotec Mark III Cyprane Comp., or Halothane-Verdunster, Drägerwerke).

Isometric tension was recorded with the help of a Grass polygraph.

\section{(d) Procedure}

It took various lengths of time for the muscle to stabilize after mounting but usually less than 30 minutes. Adaptation of the muscle to the bath could be assessed by observing the stability of resting tension.

The initial tension was set to be $0.5 \mathrm{~g}$ in the first one or two years of this study while the majority of tests were done with a baseline setting of $1.0 \mathrm{~g}$ tension. The 
muscle was stimulated every five seconds through platinum electrodes connected to a square wave generator which was usually set to deliver 2 volt impulses of 20 milliseconds duration; if necessary, the voltage was increased or decreased to produce twitches of sub-maximal height.

Whenever d-tubocurarine was used, it was added to the bath for a duration of ten minutes before any other experimentation; it never reduced the twitch height substantially, indicating that the specimens consisted of muscle without, or with only sparse fragments, of nerves and end-plates. Removal of d-tubocurarine by thorough washing preceded any other testing. It did not seem to be worth while to do the curare tests on a regular basis.

The specimens were exposed to various concentrations of caffeine which was left in the muscle bath for five minutes and then removed by washing. Initially, the enhancement by caffeine of the rate of rise of the twitch tension, as well as twitch height, were recorded, but later these parameters were disregarded because they were not readily related to caffeine concentration. The exclusively measured parameter remained the contracture produced by caffeine within four minutes. After removal of caffeine, the muscle returned within a few minutes to its state before exposure to the drug.

The first caffeine concentration tested was usually $2.0 \mathrm{mM}$. Thereafter, double concentrations were chosen for the subsequent measurements, the aim being to find those that would produce contracture tensions above and below $1 \mathrm{~g}$. At least three but usually four or five concentrations were tested for each muscle at roughly 10-minute intervals. This schedule was used to avoid distortion of the concentration-effect curves by tachyphylaxis.

Following completion of these measurements, halothane exposure was begun, and continued for one or two hours; that is, often to the end of experimentation. Since the halothane effect is not easily reversible, and since many human muscles do not respond to 1 per cent halothane alone, we decided to confine attention to the readily measurable potentiating effect of halothane upon the caffeine-produced contracture; that is, the muscle was exposed to rising caffeine concentrations, in the same manner as in the absence of halothane, starting with $0.5 \mathrm{mM}$ about 30 minutes after the beginning of the continuous flow of halothane, and following with 1,2 and $4 \mathrm{mM}$.

After termination of the caffeine test, the flow of halothane was often turned off and, about ten minutes later, succinylcholine was added to the bath for one or two minutes. Alternatively, succinylcholine was added after removal of caffeine while halothane was still flowing.

\section{(e) Evaluation}

Contracture of each muscle strip after caffeine was measured on the recording paper in terms of distance above the line which represented resting tension. With the help of calibration curves, these distances could be expressed as grams of tension increase $(\Delta g)$ in response to a given concentration of caffeine. Except for purposes of error evaluation, the tensions developed by the two strips from the same muscle were averaged for each caffeine concentration. The concentrationeffect curve was drawn by eye through these average points, using a logarithmic scale for the caffeine concentration. (For illustration of such curves see ref. 19, 
27-30.) By graphical interpolation, the caffeine concentration which caused an increase of 1 gram tension was determined.

The choice of $\Delta \mathrm{lg}$ tension implies a small workload for the mounted muscle strips which are able to develop tensions around $12 \mathrm{~g}^{*}$. On the other hand, some of the caffeine-resistant muscles never actually developed much more than $1 \mathrm{gram}$ tension increase in the test system, so that this choice permitted their inclusion in this collection of data. It was specifically established that the magnitude of this end-point was not altered by changing the baseline tension from 0.5 to $1.0 \mathrm{gram}$. Therefore, the expression of our results in terms of a percentage change would be biologically inappropriate.

Analysis of variance of the differences of response between the two muscle strips permitted the conclusion that the 95 per cent fiducial limits approached \pm 20 per cent of that caffeine concentration which is recorded as increasing the tension by 1 gram in muscle from a given patient. It should be noted that this represents an assessment of the procedural error and not of potential additional sampling errors. It is conceivable that, in subjects with muscle disease, not all muscles may be equally affected, so that collection of a healthy or diseased muscle specimen from a given subject could be a matter of chance. The only way to assess this potential sampling error would be by taking specimens from two or more different muscles of the same subject; this was not done.

\section{RESULts}

\section{(a) The control data}

The total set of measurements is shown in Figure 1. The data pertaining to malignant hyperthermia with rigidity tend to cluster in the lower left quadrant of the scatter graph, confirming the previously reported observation ${ }^{19}$ that muscle from patients with malignant hyperthermia is characterized by high sensitivity to caffeine, both in the presence and in the absence of halothane.

However, the data show a number of additional features which deserve attention. If one were to draw a line parallel to the $X$ axis, cutting the $Y$ axis at a point corresponding to $1.3 \mathrm{mM}$ caffeine, one would emphasize a natural discontinuity in the data which divides them into two groups. This is preferred over other possible divisions because it is obviously related to the ascertainment of specimens; that is, the upper cluster contains all the Other Myopathies and all except one of the amputation specimens. By contrast, none of the patients with malignant hyperthermia associated with rigidity are in that group.

It appears that there is no other straight horizontal or vertical line which would equally satisfy a simultaneous demand for a pharmacologically and clinically sensible division of the data. When attempting to unravel the complexities of these data, the first emphasis should therefore be placed on the response to caffeine in

\footnotetext{
-As a rule, the maximal tension was not measurable, since caffeine is not sufficiently soluble, and extrapolation to the maximum was not warranted since most data yielded only what seemed to be the foot of a sigmoid curve. The few completed sigmoid curves relating tension to the logarithm of caffeine concentration in the presence of 1 per cent halothane indicated a steeper slope than would be expected by a Michaelis (law of mass action) curve.
} 
KALOW, et al.: CAFFEINE TEST IN MALIGNANT HYPERTHERMIA

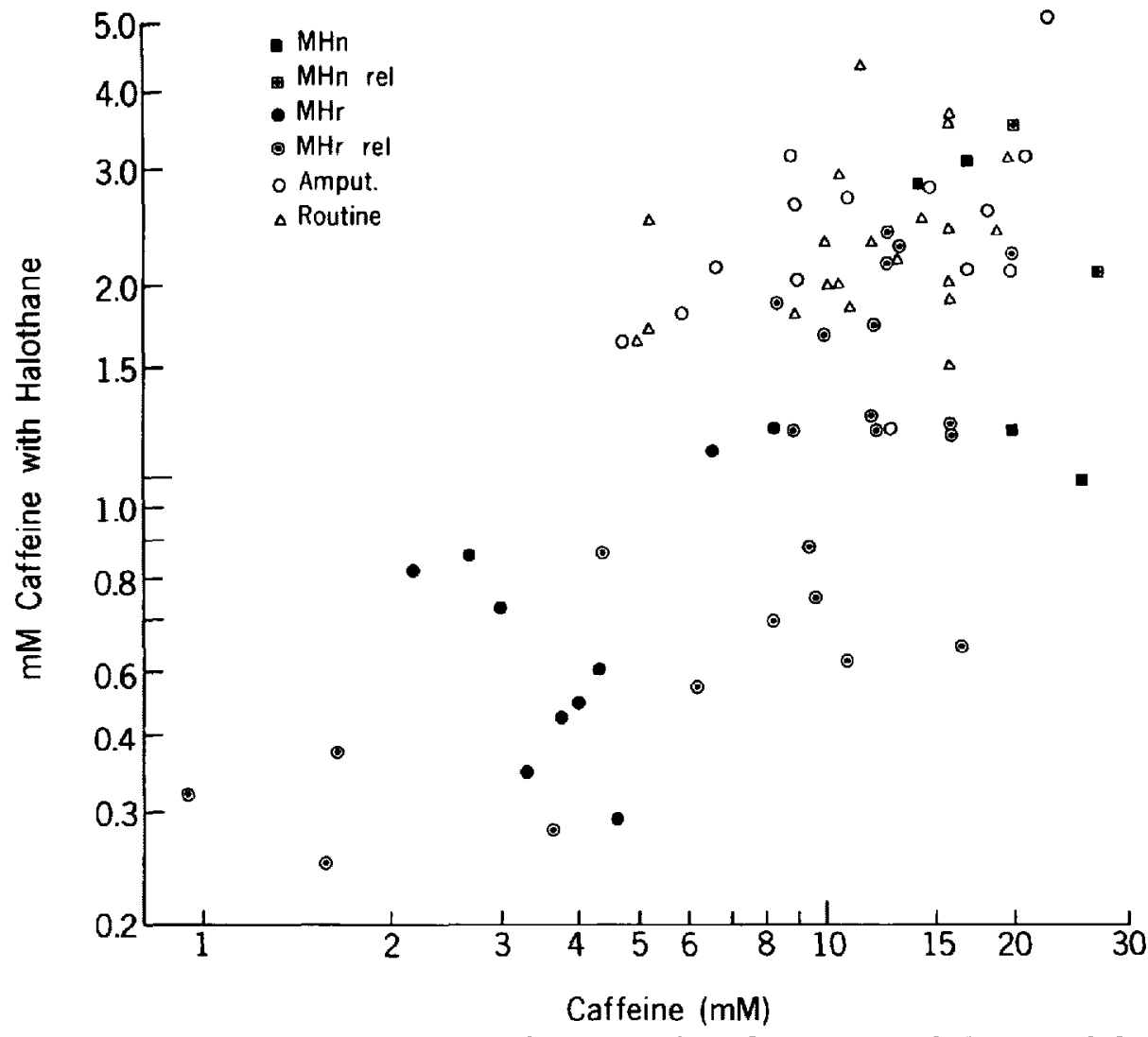

FIGUnE 1. Caffeine response of isolated human muscle in the presence and absence of halothane. The co-ordinates indicate the caffeine concentration necessary to cause a tension increase of $1 \mathrm{gram}$ in a given muscle specimen, on the $\mathrm{X}$ axis in the absence, on the $\mathrm{Y}$ axis in the presence of 1 per cent halothane in the gas phase. The different symbols indicate the categories of subjects as defined in the Methods section. MHr and MHn indicate subjects who had had an episode of malignant hyperthernia with or without rigidity, respectively. Rel refers to relatives of MH subjects, Amput. refers to muscle specimens obtained after surgery, and Myopathy indicates muscle specinens collected for neurological investigations other than $\mathrm{MH}$.

the presence of halothane. Using this criterion, the responses of 45 muscle specimens which are above the imaginary dividing line are separately shown in a probit plot in which the concentration scale is logarithmic (Figure 2, left hand curve). The linearity of the data suggests that there is a single population with random distribution of the pharmacological response to caffeine. This group is therefore designated as control group. The mean value is $2.3 \pm 0.1 \mathrm{mM}$ caffeine, while two standard deviations correspond to the range $1.26-4.17 \mathrm{mM}$ (antilog of $\bar{x}=0.36 \pm(2 \times 0.13))$. In other words, $2.3 \mathrm{mM}$ caffeine are required on the average to increase muscle tension by 1 gram if 1 per cent halothane is present in the gas phase.

The right hand curve of Figure 3 shows the response of this same control group to caffeine in the absence of halothane. The geometric mean is $11.7 \pm 0.6 \mathrm{mM}$ of 


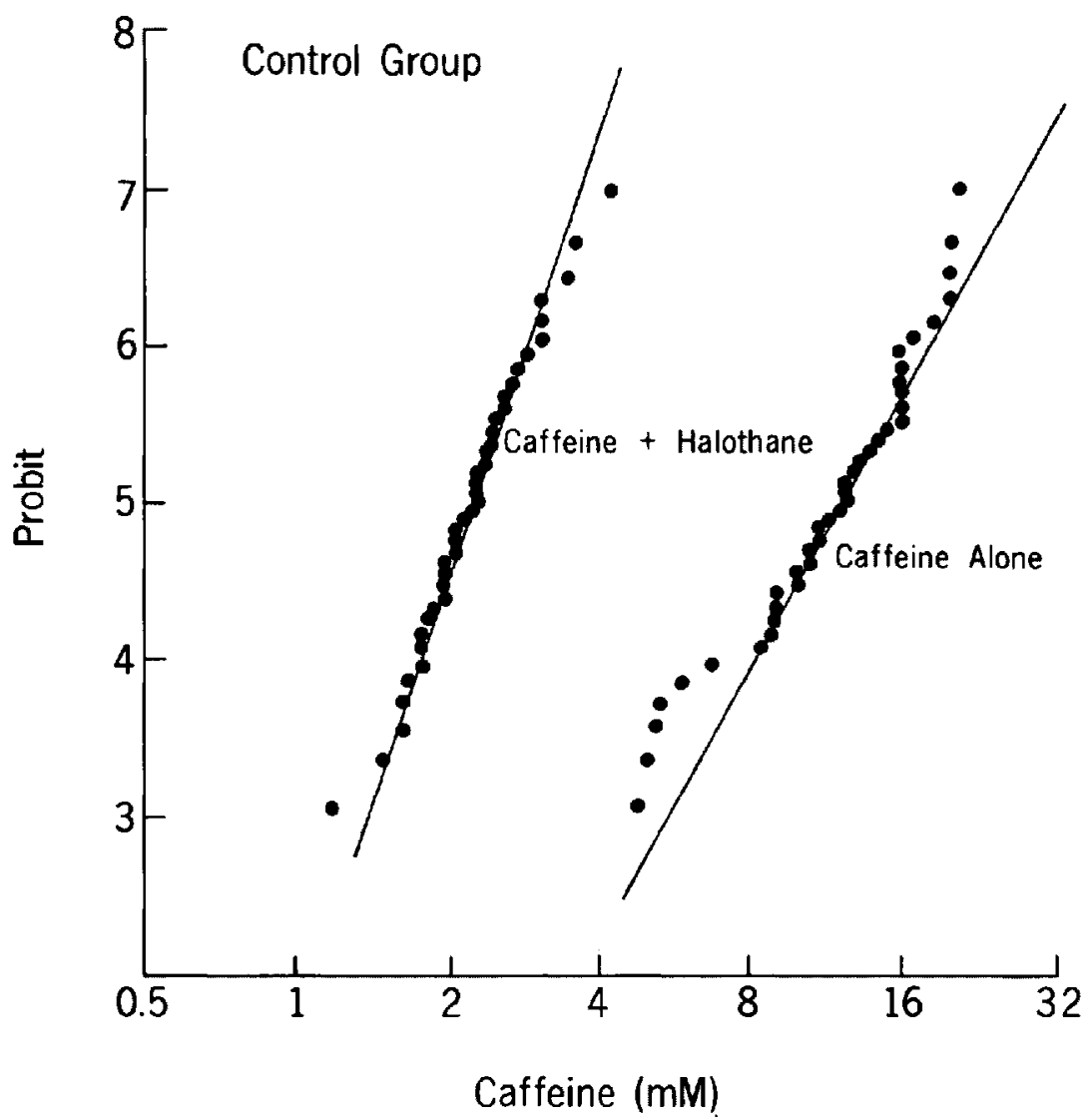

Ficure 2. Probit plots of the control group. The left-hand curve summarizes the data defined as control data; that is, specimens which require more than $1.3 \mathrm{mM}$ caffeine in the presence of halothane for the standard response. Linearity indicates fit to a Gauss distribution curve. Only the two extreme points are perhaps deviating from that distribution. The right-hand curve shows the response of the same muscle specmens to caffeine without halothane. The bulk of the data between probits 4 and 6 fits well to the straight line indicating a uniform population. The slopes of the two curves are significantly $(p<0.05)$ different which suggests that the scatter of data has biological rather than experimental calıses.

caffeine, while two standard deviations represent the range from 5.13-26.9 (antilog of $\bar{x}=1.07 \pm(2 \times 0.18))$. The data are compatible with the assumption that the control group represents a normal distribution of values, also in the absence of halothane. However, the $\mathrm{F}$ ratio of the two variances is 1.83 , which means that the difference in the scatter of data after caffeine alone, as compared to that after caffeine plus halothane, is statistically significant at the 5 per cent level. This suggests that much of the scatter of data has biological rather than experimental causes, certainly after caffeine alone, but by implication also after caffeine plus halothane. In both cases, the scatter is substantially larger than could be accounted for by experimental error (see "Evaluation" above).

We therefore attempted to identify any biological factors which would account 


\section{SUBJECTS WITH HIGH SUSCEPTIBILITY TO HALOTHANE POTENTIATION} Caffeine response in the Absence of Halothane

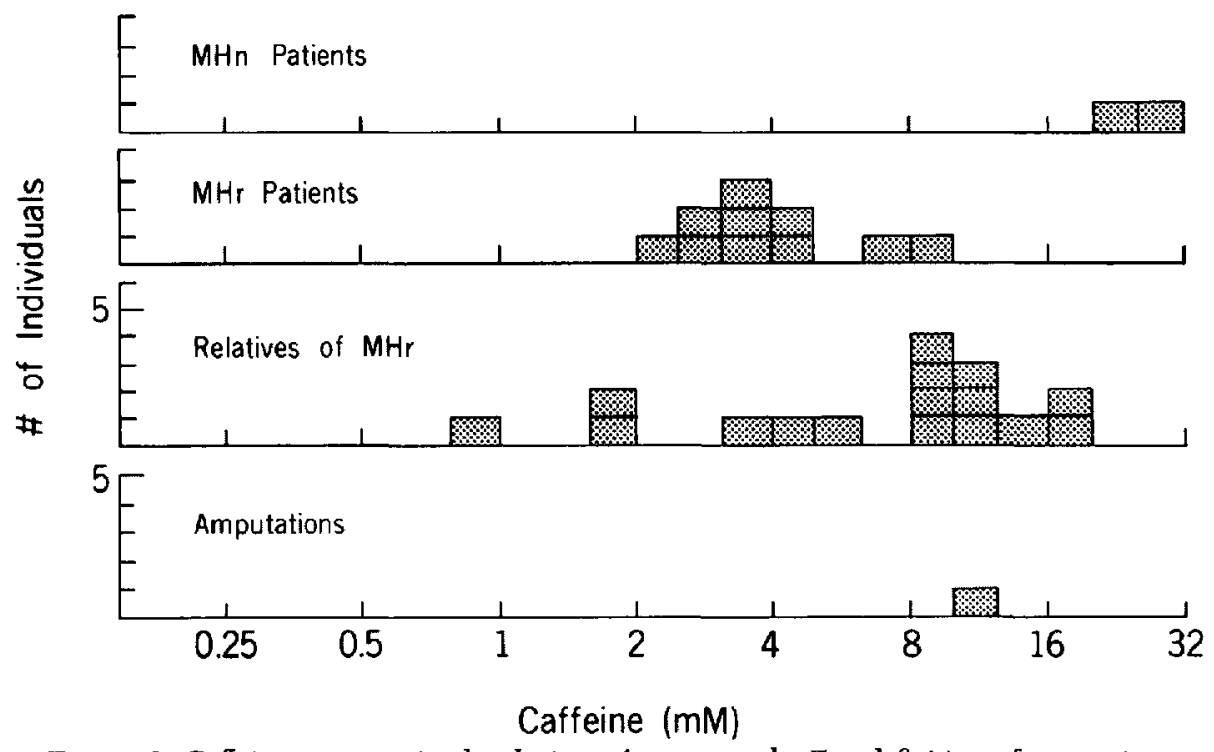

Figure 3. Caffeine response in the deviants from controls. For definition of ascertainment groups see Methods section or legend of Figure 1.

for the individual differences of caffeine response. Correlation coefficients were calculated for age and caffeine response. For caffeine alone, the coefficient was $r=-0.29$, for caffeine plus halothane $r=+0.29$. Both values were statistically not significant so that a major effect of a subject's age upon the caffeine test is unlikely. There was no discernible effect of sex on the responsiveness. The means for males and females were similar and not statistically distinguishable.

There was no systematic difference of the caffeine response between various types of human muscle, in contrast to the experiences with rodents and other vertebrates. ${ }^{31}$ This lack of difference probably reflects the fact that most human muscles consist of fairly similar mixtures of fast and slow fibres. ${ }^{32}$

Within the framework of our methods, the weight of the muscle specimens had no significant effect on the results. Although an effort was made to cut the two pieces from the same specimen in identical dimensions, they were never truly alike. As stated above, the average weight of the test strip of muscle was about $300 \mathrm{mg}$. The differences in weight within paired sections of muscle ranged from 9 to 130 mg. It turned out that there was an equal chance for the heavier and the lighter strip from a given person to react the most to caffeine. This randomness was present in the whole set of data as well as in a sub-set with the largest intra-pair differences of weight.

The caffeine response of individuals was not dependent in any obvious manner on surface phenomena. Although caffeine tended to enhance the twitch height of 
directly stimulated muscle, the magnitude of the caffeine-induced contracture was independent not only of this enhancement, but altogether was unrelated to the presence or absence of the twitch. If the muscle was electrically stimulated every five seconds but the twitch response was abolished by an excessive concentration of potassium in the bath, the caffeine contracture remained unchanged. Furthermore, among the Other Myopathies were several muscle specimens which overresponded to succinylcholine, suggesting the presence of an acetylcholine-receptor spread (to be published); this did not seem to affect the caffeine-contracture since the average and the individual responses to caffeine in this subgroup of subjects were the same as in the whole control group.

In summary, we have defined the characteristic responses of a control population to standardized caffeine tests. Within this population, the test responses are normally distributed in the statistical sense so that the population can be regarded as uniform, for the purposes of the test although it is uniform neither in terms of age, sex and state of health, nor by method of ascertainment. It is important that the definition of a control response permits the recognition of deviant responses.

It deserves to be emphasized that this control population contains nine relatives of affected subjects.

\section{(b) The Deviant Data}

Figure 3 shows the response to caffeine in the absence of halothane of those specimens which were deviant from the control group in that their muscle specimens reacted in the presence of halothane with standardized contraction to less than $1.3 \mathrm{mM}$ of caffeine. The data reveal several features. There is a gap between those patients classified as having and not having rigidity. While the occurrence of rigidity is enhanced by the use of atropine and succinylcholine, ${ }^{20}$ and while rigidity is thus no reliable criterion for a classification of patients with this syndrome, there nevertheless appear to be families and subjects which are not prone to rigidity. The two $\mathrm{MHn}$ patients are taken to represent such a special group. This group is classified as sub-normally reactive to caffeine in the presence of halothane and resistant to caffeine alone. In these two subjects the ratios of the caffeine concentrations without halothane to those with halothane were 17 and 27 . In the control group, this ratio averaged about five.

The most important feature is that the relatives of $\mathrm{MHr}$ patients cover a very much broader range than do the patients themselves. This is remarkable, particularly since the relatives with values in the control range are not represented in Figure 3. As one might expect, some of the relatives of $\mathrm{MHr}$ patients are indistinguishable from the patients in their caffeine response. This would suggest that the caffeine test has pinpointed these as having the defect which predisposes to malignant hyperthermia. However, over half the relatives shown in this figure (that is, 10 out of 16) require at least $8 \mathrm{mM}$ caffeine for the standard response, while only one of ten $\mathrm{MHr}$ paitents requires such a high caffeine concentration ( chi square $=4.8$ with $\mathrm{p}<0.05$ ).

While one may debate whether or not the dividing line should be exactly at $8 \mathrm{mM}$ caffeine and whether or not a chi square test is justified under these circumstances, the observation remains that the largest group of relatives of MHr 
KALOW, et al: : CAFFEINE TEST IN MALIGNANT HYPERTHERMLA

TABLE II

Genetics of Malignant Hyperthermia

\begin{tabular}{|c|c|c|c|c|}
\hline & & \multicolumn{2}{|c|}{ Caffeine test } & \multirow{2}{*}{$\begin{array}{l}\text { MH in } \\
\text { offspring }\end{array}$} \\
\hline & & + Haloth. & - Haloth. & \\
\hline 1 & Father & 0.35 & 1.6 & \multirow{2}{*}{2 died } \\
\hline & Mother & 0.8 & 9.4 & \\
\hline 3 & Father & 0.6 & 4.0 & \multirow{2}{*}{ died } \\
\hline 4 & Mother & 1.0 & 16.5 & \\
\hline 5 & Father & 1.7 & 12.0 & \multirow{2}{*}{ survived } \\
\hline 6 & Mother & 1.2 & 16.0 & \\
\hline 7 & Father & 1.2 & 12.0 & \multirow[b]{3}{*}{ survived } \\
\hline 8 & Mother & 0.5 & 11.0 & \\
\hline 9 & Son & 1.1 & 6.6 & \\
\hline 10 & Father's brother & 1.5 & 8.9 & \multirow[b]{3}{*}{ survived } \\
\hline 11 & Mother & 0.3 & 3.3 & \\
\hline 12 & Son & 0.3 & 9.5 & \\
\hline 13 & Father & 1.0 & 4.0 & \\
\hline 14 & Mother & 0.6 & 16.0 & died \\
\hline \multicolumn{5}{|c|}{ Controls: } \\
\hline \multirow{2}{*}{\multicolumn{2}{|c|}{$\begin{array}{l}\text { mean } \\
\pm 2 S D\end{array}$}} & 2.3 & 11.7 & \\
\hline & & $1.3-4.2$ & $5.1-26.8$ & \\
\hline
\end{tabular}

patients by this test system is different from both the control group and the affected subjects.

Thus, considering nothing but the test data per se, one can distinguish at least two kinds of $\mathrm{MH}$ patients and at least three kinds of $\mathrm{MHr}$ relatives. The words "at least" are used mainly because there are $\mathrm{MHr}$ relatives whose muscle showed extreme sensitivity to caffeine, and because of the huge spread of the ratios of caffeine requirement in the presence of halothane to that in the absence of halothane which characterizes all $\mathrm{MH}$ patients and relatives (Figure 1). Further interpretation of these test results requires that the data be put into the context of family groups (Table II).

The subjects 1 to 12 in Table II are part of $\mathrm{MHr}$ patients and relatives described in this paper; the parents numbers 13 and 14 were tested very recently and their data are listed only in this Table but were not utilized elsewhere in this paper. The ascertainment of all of the parents was through a child who had suffered an MHr attack. The family groups are all unrelated. Of the six family groups listed, four show an abnormality by the adopted criteria in both parents. In the group numbers 10 to 12 , the father could not be tested. The father number 5 is indistinguishable from controls.

\section{(c) Succinylcholine}

In spite of the clinical observation that the depolarizing muscle relaxant succinylcholine may initiate an attack of $\mathrm{MH}^{33}$ or initiate rigidity during an episode of $\mathrm{MH},{ }^{20}$ and in spite of the report by Moulds and Denborough ${ }^{20}$ that MH muscle responds to succinylcholine in vitro with contraction, the great majority 
of specimens showed no response to succinylcholine in our test system. Succinylcholine contraction was produced in only one of six MHr patients tested, in one of four MHn patients and in four of $19 \mathrm{MHr}$ relatives. There was no evidence of familial occurrence of this response. The frequency of this response among the group of Other Myopathies will be the subject of a special report: we found succinylcholine to produce contraction particularly in myotonia and, unexpectedly, in polymyositis and apparently related auto-immune diseases. When specifically tested, the occurrence of succinylcholine contraction proved to be an all-or-none response; that is, an unresponsive muscle remained unresponsive regardless of succinylcholine concentration.

\section{Discussion}

When malignant hyperthermia was first studied by pharmacological tests in human muscle, the procedure was a novelty. ${ }^{19}$ The initial observation was an abnormal sensitivity to caffeine of isolated muscle from $\mathrm{MH}$ patients, whether or not halothane was present. The presence of halothane potentiated the caffeine effect and seemed slightly to improve the distinction between affected and nonaffected subjects. However, the intensity of the halothane potentiation (i.e. the ratio of caffeine concentrations required to produce a standard contraction in the absence and in the presence of halothane) was not significantly altered in affected muscle. ${ }^{19}$ All these observations are confirmed in this paper.

In this initial test series, halothane alone did not cause contraction of either $\mathrm{MH}$ or normal muscle, even though the concentration was raised up to 5 per cent in the gas phase. In retrospect it appears that there must be exceptional $\mathrm{MH}$ muscles which do not respond to halothane without caffeine, since Ellis, et al. ${ }^{21}$ later reported that halothane alone would selectively cause contraction of $\mathrm{MH}$ muscle, usually requiring 2 to 4 per cent halothane in the bubbling gas. Moulds and Denborough, ${ }^{14}$ and Harriman et al. ${ }^{34}$ and Bradley and Marchison ${ }^{22}$ used the halothane-induced contraction for diagnostic purposes.

The halothane test of Ellis, et al..$^{21}$ is a qualitative or an all-or-none test; that is, the criterion is whether the muscle does or does not contract on exposure to halothane. The test is qualitative not only because of lack of response of normal muscle. Even if the muscle is susceptible, a halothane concentration of 1 per cent acts only exceptionally, or after a stretching manipulation, ${ }^{24}$ while 5 per cent may produce irreversible damage. After exposure of the isolated muscle to halothane, removal of the halothane does not permit the muscle to go back to its original state of relaxation, or only after periods of time which are long in terms of the functional survival of isolated muscle. This does not encourage the construction of dose-effect curves with halothane. On the other hand, the essence of the caffeine test is the characterization of the muscle by measured values which are produced with the help of concentration-effect curves. The potential information content of pharmacological data based on measurements is generally greater than that of all-or-none data.

Ellis, et al. ${ }^{21,24}$ recommended the search for and collection of muscle specimens which contained nerve endplates. This recommendation is redundant in view of 
the nature of the test drugs and in view of the lack of influence of curare on the test (see Methods section).

There is no need to use the drugs with which the patient may get into trouble as the yardstick for assessing the muscle. Indeed, the caffeine concentrations used here are greater than would ever occur in the living subject. It is an important fact that the principal mode of action of caffeine in causing muscular contraction is reasonably well known. It consists of the intracellular release of calcium from the sarcoplasmic reticulum ${ }^{25,86}$ and perhaps from the sarcolemma ${ }^{37}$ The caffeine test gives some indication where the defect predisposing to $\mathrm{MH}$ must lie. The mode of action of halothane is probably similar to that of caffeine. ${ }^{19}$ However, since the halothane potentiation of the caffeine effect is as variable as our data indicate, the two drugs cannot have precisely the same action, at least not at the halothane concentrations used here.

The family data which are available to date enforce a new look at the inheritance of the predisposition to $\mathrm{MH}$, but they are not extensive enough to warrant firm decisions between alternative possibilities of genetic transfer. Since there seem to be at least four different phenotypes among the MHr-connected subjects listed in Table II (e.g. numbers 1, 2, 4 and 5), more than one mutant locus must be postulated. There is no suggestion of multigenic inheritance. Multigenic by genetic definition means an involvement of three or more pairs of genes and is characterized by a continuous (Gaussian) distribution of a trait in the population. Here, the Gaussian distribution pertains to the control population (Figure 2) which differs distinctly from the affected remainder of the population. If one can thus exclude multifactorial inheritance as very unlikely, it is equally clear that there must be more than one genetic locus involved in the predisposition to $\mathrm{MHr}$. This could be two pairs of genes, giving rise to nine genotypes. This assumption is favoured because of the partial independence of the caffeine and caffeine-halothane responses; thus, one seems to deal with two different though overlapping traits which could be readily accounted for by a two-gene hypothesis.

However, the present data do not allow one to exclude the following alternative:

Perhaps the simplest genetic hypothesis to explain all the data may be the assumption of three alleles, $\underline{\mathrm{MH}}, \underline{\mathrm{MHr}}$, and $\underline{\mathrm{MH}} \mathbf{3}$ on the same locus. This would lead to the further assumption that $\mathrm{MH}^{3}$ represents functionally a gross abnormality and $\underline{\mathrm{MHr}}$ a minor alteration. The minor alteration in double dose in the phenotype MHr 2-2 would constitute the recessive form of malignant hyperthermia, while a single dose of the more severely altered gene in $\mathrm{MHr}$ 1-3 subjects would account for the dominant form. In short, alterations on the same gene locus could give the picture of sometimes dominant sometimes recessive inheritance. As a consequence of this concept one might have to assume that homozygotes $\mathrm{MHr}$ 3-3 are not viable. This would leave five viable genotypes.

This concept could account for a grading of $\mathrm{MH}$ by the propensity to suffer an attack and might explain the clinical impression of differences in the severity of an attack. Persons who develop an $\mathrm{MH}$ attack only under conditions especially favourable for it may be heterozygous $\mathrm{MHr}$ 1-2 subjects. Increasing severity or likelihood of an attack would be represented by the series $\mathrm{MHr} 1-2, \mathrm{MHr} 2-2$, MHr 1-3 and MHr 2-3. The two children of subjects one and two in Table II may 
have been of this latter genotype. They died quickly and with extreme rigidity so that their bodies were arched upwards and supported by head and heel.

Since carriers of a recessive gene are always more frequent in a population than are the rarer of the two homozygotes, it may not be surprising that one person was found among the donors of the amputation specimens who was unconnected with malignant hyperthermia and yet reacted in the test system like an $\mathrm{MHr}$ 1-2 subject. If the observations of one affected among 35 unsuspected specimens is representative, this MH carrier status would not be rare at all.

We stressed the concept of a genetic difference between rigid and some nonrigid cases by referring to "MHr" and "MHn." Originally" this concept was introduced merely as an arbitrary aid to the statistical exploration of data. It is now known from epidemiological data that the choice of drugs may determine whether MHr patients will develop rigidity during a hyperthermia attack, ${ }^{20}$ but $\mathrm{MHn}$ patients are thought never to develop rigidity. For instance, a previously published large pedigree contained exclusively $\mathrm{MHn}$ subjects, ${ }^{4}$ that is, none of the 21 clinically affected subjects had ever developed rigidity. Thus, MHn obviously runs in families which are different from MHr families. The observation of dominance of the genetic trait in this large published pedigree ${ }^{t}$ preceded the distinction between different kinds of malignant hyperthermia and probably helped to foster the idea that every hereditary predisposition to $\mathrm{MH}$ should be dominant.

Concerning current data, one may notice that in four of the six MHn related or affected subjects the values for caffeine alone were among the highest observed in the whole study. We are sure that muscle resistance to caffeine is a genuine occurrence. We reported previously ${ }^{28}$ a family with high susceptibility of skeletal and cardiac muscle to damage by small amounts of ethanol. In the one subject that could be tested, $32 \mathrm{mM}$ caffeine caused a tension increase of only $0.55 \mathrm{~g}$ so that a reliable extrapolation to one gram was impossible. In the presence of halothane, $9 \mathrm{mM}$ of caffeine were necessary to produce the standard effect. This case was exceptional and a connection with MHn was not established. Nevertheless, it seems best to adopt the working hypothesis that $\mathrm{MHn}$ is due to a defect at a different locus than $\mathrm{MHr}$.

The method described in this report permits hitherto unobtainable distinctions between apparently "healthy" skeletal muscles of different subjects. This is perhaps the most important result, since there are many functional variants of human muscle which are insufficiently understood and which are expressed as differences in athletic prowess, trainability, susceptibility to hernias, or muscle-induced skeletal deformities. The study of these and other deviations calls for new investigational approaches; pharmacological assays of various kinds may provide some answers.

\section{SUMMARY}

1. Pharmacological tests of isolated fibers of skeletal muscle proved to be a means of clarifying the occurrence of certain genetic defects.

2. Muscle specimens from 74 subjects were investigated. Of these, 14 had recovered from an episode of malignant hyperthermia $(\mathrm{MH})$, an often fatal complication of general anaesthesia which is known to occur on the basis of a genetic 
predisposition. The others were 25 relatives of $\mathrm{MH}$ patients, and 35 subjects unrelated to malignant hyperthermia.

3. The tests consisted in measuring the contracture tensions of isolated fibres of skeletal muscle when exposed to various concentrations of caffeine, once in the presence, once in the absence of the anaesthetic agent halothane. The method is described in detail.

4. Muscle specimens which in the presence of halothane required more than 1.3 millimolar concentration of caffeine to produce a tension increase of 1 gram were defined as controls. The 45 control data thus defined were normally distributed. Age, sex, type of muscle, and size of the specimen did not account for individual difference within this control population. The control group did not contain any $\mathrm{MH}$ patient who had developed rigidity during the attack. On the other hand, it did contain all but one of the specimens from $\mathrm{MH}$-unrelated subjects.

5 . The acceptance of the control data as a standard left a deviant group of 29 subjects. This group could be subdivided according to the caffeine-contracture in the absence of halothane.

All those $\mathrm{MH}$ patients who had displayed some rigidity during their attack were in this deviant group; they were characterized by high sensitivity to caffeine. The deviant group included two subjects who had suffered an $\mathrm{MH}$ episode without rigidity; they differed from all others by a high resistance to caffeine contracture and thereby seemed to represent a separate category of $\mathrm{MH}$ which could not be further analyzed during the studies reported here.

The deviant group contained 10 relatives of $\mathrm{MH}$ patients who differed in their caffeine response from the patients themselves. Hence there are at least three kinds of relatives of $\mathrm{MH}$ patients: those that are indistinguishable from patients, those that fall into the control group, and an intermediate group. One of the MH-unrelated subjects reacted like an intermediate, suggesting that this represents a defect which is not rare in the general population.

6 . When these data were seen in the context of family groups, there was evidence of a recessively inherited predisposition to malignant hyperthermia. However, part of the data were also compatible with the repeatedly published evidence of dominant inheritance of this predisposition. Since multigenic inheritance appears to be excluded, the simplest genetic models which can reasonably account for the observations are either a two-gene case or the assumption of one gene locus with three alleles. Improvement of the test methods or an increase of the data base should allow a choice between genetic theories.

\section{RÉSUMÉ}

1. Il existe maintenant des tests pharmacologiques sur des fibres musculaires squelettiques permettant de mettre en évidence certaines anomalies génétiques.

2. Essentiellement, il s'agit de mesurer les tensions de contraction des fibres musculaires isolées lorsque celles-ci sont mises en présence de solution de caféine à des concentrations diverses avec ou sans halotane.

3. Dans ce travail, des spécimens musculaires provenant de 74 malades ont été étudiés. Parmi ces malades, 14 étaient des survivants d'un épisode d'hyperthermie 
maligne (HM). Vingt-cinq autres échantillons provenaient de parents de malades avec une histoire d'hyperthermie maligne. Les 35 autres provenaient de patients sans antécédents personnels ou familiaux d'hyperthermie maligne.

4. Des spécimens musculaires qui nécessitaient en présence d'halotane plus de 1.3 millimoles de caféine pour produire une élévation de tension de $1 \mathrm{~g}$ ont été considérés comme spécimens témoins. Quarante-cinq des spécimens correspondaient à cette définition. L'âge, le sexe et le type de muscle prélevé n'étaicnt sans aucune relation avec le résultat obtenu.

Aucun des spécimens venant de malades à antécédents personnels d'hyperthermie maligne avec rigidité musculaire ne s'est classé dans ce groupe; d'autre part, 34 des 35 sujets sans aucun antécédents ou parenté suspecte se sont classés dans ce groupe.

5. Si l'on accepte ce groupe témoin comme normal, nos résultats nous permettent d'identifier un groupe de 29 sujets déviants que l'on peut subdiviser en sous-groupes selon la réaction à la caféine en l'absence d'halotane:

- Un premier sous-groupe caractérisé par sa grande sensibilité à la caféine, groupe où l'on retrouve tous les malades avec antécédents d'hyperthermie maligne accompagnée de rigidité.

- Un deuxième sous-groupe caractérisé par une grande résistance à la caféine, groupe qui inclut deux sujets avec antécédents d'hyperthermie maligne mais dont l'attaque ne s'était pas accompagnée de rigidité. Ce sous-groupe nous semble représenter une catégorie particulière qu'il fut impossible d’étudier plus avant dans ce travail.

- Dans le groupe déviant, on retrouve plusieurs sujets apparentés à des malades à antécédents positifs. Or, 10 de ces sujets présentent une réponse à la caféine différente de celle de leurs parents malades. Ainsi, il semble y avoir trois types de parents de malades positifs: les uns répondant exactement comme les malades, d'autres comme des gens normaux et un groupe intermédiaire.

Un des sujets sans antécédents ni parenté a présenté la réaction intermédiaire ce qui suggère la présence dans la population d'un défaut génétique qui ne serait pas très rare.

6. Lorsque l'on confronte ces résultats aux groupes familiaux, on perçoit la présence d'une prédisposition héréditaire de caractère récessif dans l'hyperthermie maligne. Cependant, une partie des résultats obtenus est également compatible avec les nombreux rapports soulignant la transmission à caractère dominant de cette pathologie.

\section{ACKNOWLEDGEMENTS}

Dr. Laszlo Endrenyi provided many helpful suggestions in the course of numerous discussions. We gratefully acknowledge competent technical assistance of Mrs. Mary Terreau and Mrs. Rosemary Gage.

We are deeply indebted to the staff of the Farquharson Clinical Investigation Unit of the Toronto General Hospital who provided hospital care for the MHS patients and relatives investigated in this study.

\section{REFERENCES}

1. GoRdon, R.A., BRITT, B.A., \& Kalow, W. (eds.) International symposium on malignant hyperthermia. Springfield, Thomas, 512 pages (1973). 
2. Britr, B.A. Malignant hyperthermia: a pharmacogenetic disease of skeletal and cardiac muscle. N. Engl. J. Med. 290: 1140-1142 (1974).

3. Denborough, M.A., Forster, J.F.A., Maplestone, P.A., \& Villiers, J.D. Anaesthetic deaths in a family. Br. J. Anaesth, 34: 395-396 (1962).

4. Britt, B.A., Locher, W.G., \& Kalow, W. Hereditary aspects of malignant hyperthermia Can. Anaesth. Soc. J. 16;89-98 (1969).

5. Denborough, M.A., Ebeling, P., King, J.O., \& Zapf, P. Myopathy and malignant hyperthermia. Lancet I: $1138-40$ (1970).

6. IsAACs, H. \& BARLOW, M.B. The genetic background to malignant hyperpyrexia revealed by serum creatine phosphokinase estimations in asymptomatic relatives. Br. J. Anaesth. 42 : $1077-1084(1970)$.

7. Kyei-Mensah, K., Lockwood, R., Tyrket, , J.H., \& Willett, I.H. Malignant hyperpyrexia: a study of a family. Br. J. Anaesth. 43: 811-812 (1971).

8. JAFFe, E.C. \& WEdley, J.R. Malignant hyperpyrexia: an anaesthetic hazard, Br. Dent. J. 133: 538-541 (1972).

9. Kins, J.O., Denbonough, M.A., \& ZAPF, P.W. Inheritance of malignant hyperpyrexia. Lancet I: $365-370$ (1972).

10. Parikn, R.K. \& Thomson, W.H.S. Malignant hyperthermia: a fatal case and his family. Br. J. Anaesth. 44: 742-746 (1972).

11. Zsigmond, E.K., Starkweather, W.H., Duhoff, G.S., \& Flynn, K. Elevated serumcreatine phosphokinase activity in a family with malignant hyperpyrexia. Anesth. Analg. 51: 220-225 (1972).

12. IsAaCs, H. \& BARLow, M.B. Malignant hyperpyrexia occurring in asecond Johannesburg family. Br. J. Anaesth.. 45: 901-906 (1973)

13. Kalow, W. \& Britr, B.A. Inheritance of malignant hyperthermia. In International Symposium on Malignant Hyperthermia (eds. Gordon, Britt, Kalow). Springfield, Thomas, pp. $67-76$ (1973).

14. Moulds, R.F.W. \& Denbonough, M.A. Identification of susceptibility to malignant hyperpyrexia. Br. Med. J. 2: 245-247 (1974).

15. Kaukinen, S., Stenterg, J., \& Kaukinen, L. A fatal case of malignant hyperthermia during anaesthesia and a study on the patients blood relatives. Ann. Chir. Gynaecol. Fenn. 63: 212-216 (1974).

16. La Coun, D., Juul-Jensey, P., \& Reske-Nielsen, E. Malignant hyperthermia during annesthesia: a neurophysiological and neuropathological follow-up study of a patient and his family. Acta Anaesthesiol. Scand. 15: 299-317 (1971).

17. Zisigmond, E.K., Stankweather, W.H., Duboff, G.S., \& Flynn, K.A. Abnormal creatinephosphokinase isoenzyme patterns in families with malignant hyperpyrexia. Anesth. Analg. 51: 827-840 (1972).

18. Kelstrup, J., HaAse, J., Jónni, J., Reske-Nielsen, E., \& Hanel, H.K. Malignant hyperthermia in a family. Acta Anaesth. Scand. 17: 283-284 (1973)

19. Kalow, W., Britt, B.A., Terheau, M.E., \& Haist, C. Metabolic error of muscle metabo]ism after recovery from malignant hyperthermia. Lancet II: 895-898 (1970).

20. Kalow, W. \& BRITt, B.A. Drugs causing rigidity in malignant hyperthermia. Lancet 2: 390-391 (1973)

21. Ellis, F.R., Keaney, N.P., Harriaran, D.G.F., Sumner, D.W., Kyei-Mensah, K., Tyrrell, J.H., Harcheaves, J.B., Parikh, R.K., \& Mulrooney, P.O. Screening for malignant hyperpyrexia. Br. Med. J. 3: 559-561 (1972).

22. Bradley, W.G. \& Murchison, D. Screening for malignant hyperpyrexia. Br. Med. J. 4: 108-109 (1972).

23. Moulds, R.F.W. \& Dendonouch, M.A. Procaine in malignant hyperpyrexia. Br. Med. J. 4: 526-528 (1972).

24. Elilis, F.R. \& Harkiman, D.G.F. A new screening test for susceptibility to malignant hyperpyrexia. Br. I. Anaesth. 45: 638 (1973).

25. Moulds, R.F.W. \& Denborough, M.A. A study of the action of caffeine, halothane, potassium chloride and procaine on nomal human skeletal muscle. Clin. Exp. Pharnacol. Physiol. 1: 197-209 (1974).

26. Moulds, H.F.W. \& Denborough, M.A. Biochemical basis of malignant hyperpyrexia. Br. Med. J. 241-244 (1974).

27. Kalow, W. Succinylcholine and malignant hyperthermia. Fed. Proc. 31: 1270-1275 (1972).

28. Kalow, W. Pharmacogenetics of drugs used in anaesthesia. Human Genetics. (Proc. 4th 
Int. Congr. Hum. Genet., Paris, 6-11, September 1971.) Annsterdam (Excerpta Medica) pp. 415-427 (1972).

29. KaLow, W. Genes controlling drug actions in man. Pharmacology and the future of man. Proc. 5th Int. Congr. Pharmacology, San Francisco, 1972, 3: pp. 2-16 (Karger, Basel, 1973).

30. Britt, B.A., Kalow, W., Gondon, A., Humphrey, J.G., \& Rewcastle, N.B. Malignant hyperthermia: an investigation of five patients. Canad. Anaesth. Soc. J. 20: 431-467 (1973).

31. IsaAcson, A., Hinkes, M.J., \& Taylor, S.R. Contracture and twitch potentiation of fast and slow muscles of the rat at 20 and $37^{\circ} \mathrm{C}$. Am. J. Physiol. 218: 33-41 (1970).

32. Humphrey, J. Personal communication.

33. Brits, B.A. \& Kalow, W. Malignant hyperthermia: a statistical review. Canad. Anaesth. Soc. J. 17: 293-315 (1970).

34. Harriman, D.G.F., Sumner, D.W., \& Ellis, F.R. Malignant hyperpyrexia myopathy. Q. J. Med. 42: 639-664 (1973).

35. WEBER, A. The mechanism of the action of caffeine on sarcoplasmic reticulum. J. Gen. Physiol. 52: 760-772 (1968).

36. SAndow, A. Skeletal muscle. Ann. Rev. Physiol. 32: 87-138 (1970).

37. Thorpe, W.R. \& Seeman, P. Effect of denervating skeletal muscle on calcium binding by isolated sarcolemma. Exp. Neurol. 30: 277-290 (1971). 